\title{
Dose response inhibition in man of meal-stimulated gastric acid secretion by 15(R)-15-methyl prostaglandin $\mathrm{E}_{2}$, given orally
}

\author{
A ROBERT, G KANE, AND S B REELE* \\ From the Bronson Clinical Investigational Unit, The Upjohn Company, Kalamazoo, \\ Michigan, USA
}

SUMMARY 15(R)-15-methyl prostaglandin $E_{2}$ was given orally to healthy male volunteers. Thirty minutes later a $10 \%$ peptone meal was introduced into the stomach, and the acid response was measured by continuous intragastric titration with $0.5 \mathrm{~N} \mathrm{NaOH}$ for the next two hours. The prostaglandin inhibited acid output in a dose dependent manner; the ED $_{50}$ (dose inhibiting acid output by $50 \%$ ) was as little as $10 \mu \mathrm{g}$ per subject (or approximately $140 \mathrm{ng} / \mathrm{kg}$ ). This compound is the most potent orally active inhibitor of gastric acid secretion in man that is known. It is likely that the antisecretory and cytoprotective properties shared by $15(\mathrm{R})-15$ methyl prostaglandin $E_{\text {: }}$ would be beneficial in the treatment of peptic ulcer and in preventing recurrences.

Several natural prostaglandins such as $\mathrm{PGE}_{1}$. $\mathrm{PGE}_{2}, \mathrm{PGA}_{1}$, and $\mathrm{PGA}_{2}$ were found to inhibit gastric acid secretion in animals ${ }^{123}$ and humans ${ }^{45}$ when administered parenterally, although they are inactive or very weak when given orally. "i : Certain methyl analogues of PGE $_{2}$ are also antisecretory but differ from $\mathrm{PGE}_{2}$ in that they are active orally, are long-acting, and are many times more potent than the parent compound. " Such an analogue is $15(\mathrm{R})-15$-methyl prostaglandin $E_{2}$ (M-PGE, arbaprostil) which was previously shown to inhibit acid secretion in humans. ${ }^{10-11}$ We report here the effect of various doses of $\mathrm{M}-\mathrm{PGE}_{2}$, given orally, on gastric acid output stimulated by a meal. The purpose was to establish a dose response curve. The results show that M-PGE 2 is one of the most potent antisecretory agents in humans when given by the oral route.

\section{Methods}

Twenty-five healthy male volunteers between 18 and 27 years old were studied (Table 1). Informed

*Address for reprint requests: Dr S B Reele, Bronson Clinical Investigational Unit, 252 East Lovell Street, Kalamazoo, Michigan 49007 USA.

Received for publication 10 March 1981 consent was provided by each subject. They were without gastrointestinal symptoms and had normal values for blood chemistry, haematology, and urinalysis. A physical examination and an electrocardiogram were normal. After an overnight fast $(10.00 \mathrm{pm})$, an 18-gauge French double-lumen Salem tube was introduced into the stomach. The subjects were semi-reclined in a lounge chair for the rest of the study. The gastric contents were

Table 1 Characteristics of study population

\begin{tabular}{lll}
\hline $\begin{array}{l}\text { Drug group } \\
(\mu g)\end{array}$ & Age $(y r)$ & Weight $(\mathrm{lb})$ \\
\hline 10 & $20 \cdot 8+1 \cdot 9$ & $164 \cdot 3 \pm 16 \cdot 4$ \\
& $(19-24)$ & $(151-191)$ \\
25 & $27 \cdot 4+3 \cdot 8$ & $176 \cdot 5 \pm 14 \cdot 1$ \\
& $(22-30)$ & $(157-196)$ \\
50 & $25 \cdot 2 ! 6 \cdot 6$ & $162 \cdot 4+5 \cdot 1$ \\
& $(21-37)$ & $(156-168)$ \\
100 & $26 \cdot 8+5 \cdot 7$ & $174 \cdot 8 \pm 25 \cdot 8$ \\
& $(19-33)$ & $(154-217)$ \\
150 & $26 \cdot 4+5 \cdot 2$ & $173 \cdot 8 \pm 24 \cdot 1$ \\
& $(18-32)$ & $(137-203)$ \\
\hline
\end{tabular}

$* \bar{x}: S D$.

The mean age and weights of the five different groups of five volunteers each.

There was no statistically significant difference between the ages and weights of the different groups. 
emptied by gravity and gentle suction. Either drug or placebo was then administered in $15 \mathrm{ml}$ of an aqueous solution through the nasogastric tube, which was then clamped for 30 minutes. After that time, $600 \mathrm{ml}$ of a $10 \%$ peptone meal (BactoPeptone, Difco Laboratories, Detroit, Michigan) adjusted to $\mathrm{pH} 5 \cdot 5$ with $\mathrm{HCl}$ was introduced into the stomach through the nasogastric tube. Acid output was measured by an intragastric titration method previously described. ${ }^{12} 13$ Briefly, $32 \mathrm{ml}$ of the gastric contents were aspirated and returned to the stomach eight times per minute with the use of an automatic pipetting machine (Brewer, Model 60453, Scientific Equipment Products, Baltimore, Maryland). The $\mathrm{pH}$ of the gastric contents was detected by a $\mathrm{pH}$ electrode (Standard pH meter. Model DHM-62, Radiometer, Copenhagen) located between the nasogastric tube and the automatic pipette. When the $\mathrm{pH}$ fell below 5.5 as a result of acid secretion by the stomach, $0.5 \mathrm{~N}$ sodium hydroxide was delivered by an automatic titrator (Radiometer, Model TTT60) directly into the stomach via the smaller lumen of the nasogastric tube. The titration was continued for two hours. The amount of $\mathrm{NaOH}$ administered to keep the gastric $\mathrm{pH}$ constant at 5.5 was recorded on graph paper and the total amount thus delivered per 15 minute intervals was used for calculation. These values were analysed by a two-way analysis of variance, the differences among the five dose levels were analysed by the Kruskal-Wallis test, and the pairwise comparisons obtained by the Wilcoxon test.

The subjects were divided into five groups, each group receiving a different dose of M-PGE. These doses were $10,25,50,100$, and $150 \mu \mathrm{g} /$ subject. Each subject participated twice during the study, one day receiving placebo and the other day one of the doses of M-PGE. The two studies were separated by one week. The treatments were randomised and administered in a double-blind manner. M-PGE, was supplied as a solution of $250 \mu \mathrm{g} / \mathrm{ml}$ dissolved in triacetin, and diluted on the morning of each study with water to a volume of $15 \mathrm{ml}$.

\section{Results}

M-PGE: inhibited food-induced acid output, and the effect was dose-dependent. Table 2 gives the mean acid output, in $\mathrm{mmol} / 15 \mathrm{~min}$, for each time interval and at each dose level. Since the response to the meal alone (meal plus placebo) varied between individuals, the results were also expressed for each dose level as percent of the placebo re- sponse (Fig. 1). This Figure shows that doses of 100 and $150 \mu \mathrm{g}$ produced near total inhibition of acid secretion.

Figure 2 shows that the antisecretory effect was dose-dependent when the dose is plotted on a logarithmic scale. The $\mathrm{ED}_{5,0}$-that is, the dose inhibiting acid output by $50 \%$-was $10 \mu \mathrm{g} /$

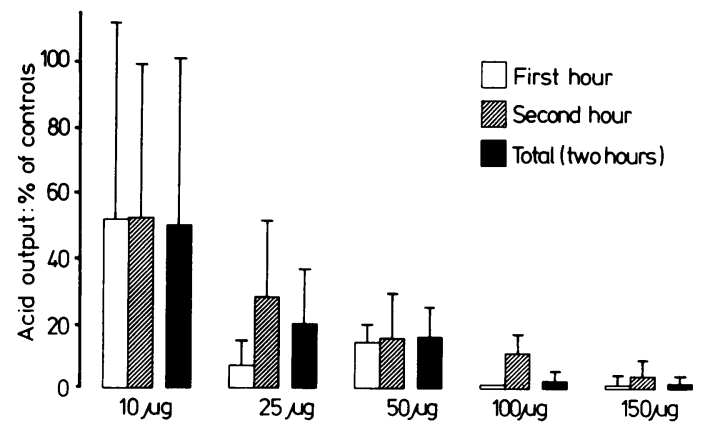

Fig. 1 Antisecretory effect of $15(R)-15$ methyl $P G E_{.2}$. Results are expressed as percentage of controls. For doses of $25 \mu \mathrm{g}$ and higher, all values for each dose were statistically different $(\mathrm{P}<0.05)$ from those obtained in control (placebo) studies.

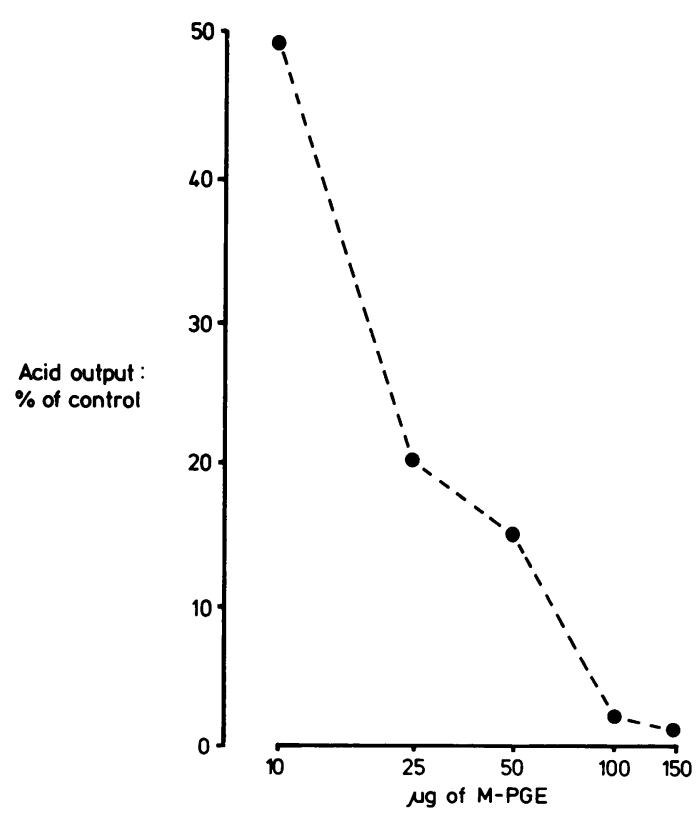

Fig. 2 Dose response inhibition of meal-induced acid output by 15(R)-15 methyl PGE. The ED 50 is $10 \mu g$ per subject, when the doses are plotted on $a$ logarithmic scale. 
Table 2 Mean acid secretion $(\mathrm{mmol} / 15 \mathrm{~min}$ ) during placebo treatment and drug treatment

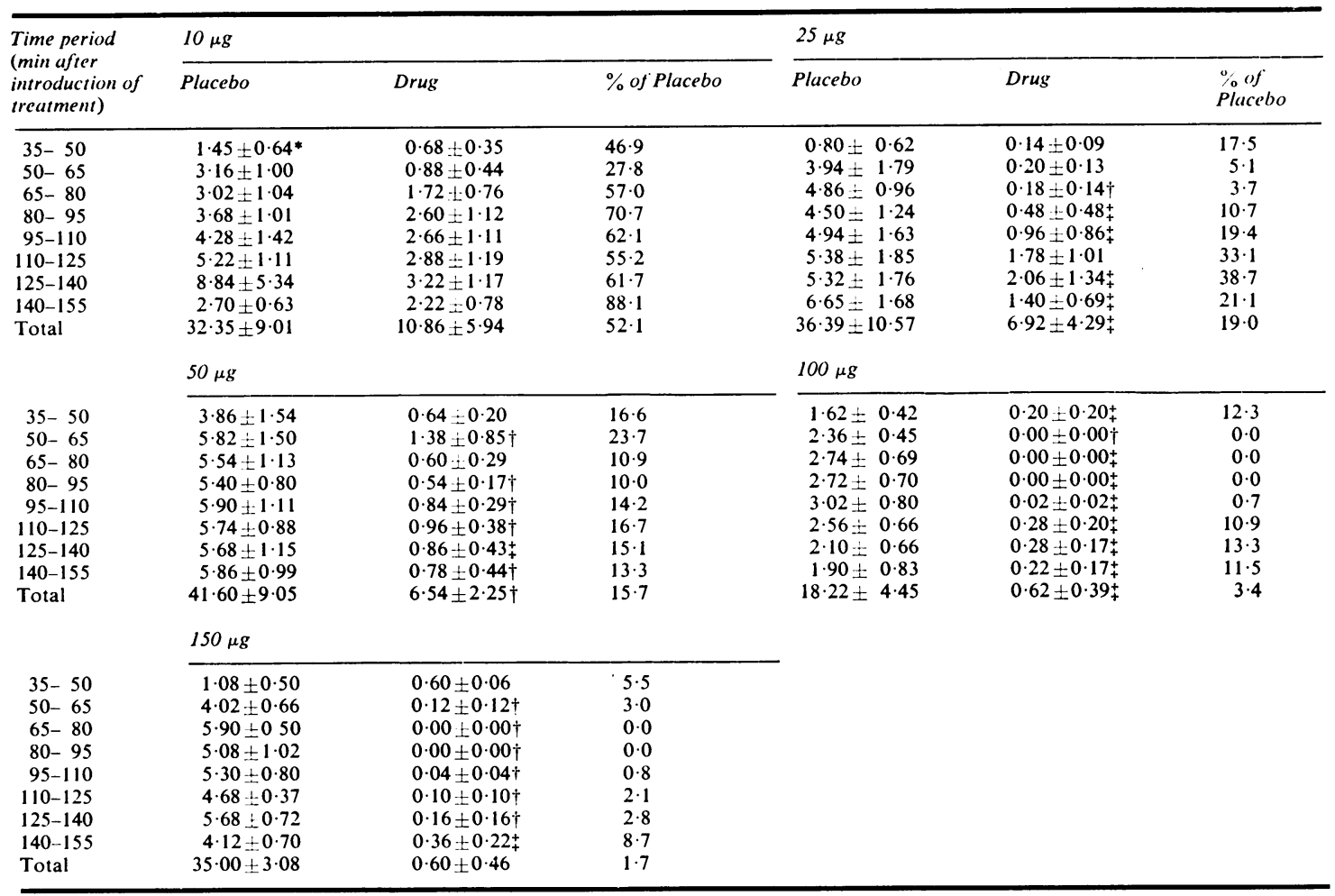

* $\overline{\mathrm{x}}: \mathrm{SEM}$.

$\dagger$ Significantly lower than mean acid secretion during placebo treatment $\mathrm{P}<0.01$. $\pm \mathrm{P}<0.05$.

The mean mmol of acid secreted per 15 minute time intervals for each group during two hours of meal stimulated intragastric titration. Acid secretion was measured by mmol of base $(0.5 \mathrm{~N} \mathrm{NaOH})$ titrated to maintain intragastric pH constant at $5 \cdot 5$.

subject, or approximately $140 \mathrm{ng} / \mathrm{kg}$. Although the total duration of action was not determined, as illustrated in Fig. 1, it is clear that the antisecretory effect was near maximal, for each dose, for the $2 \frac{1}{2}$ hours after administration of the prostaglandin, at which time the study was terminated.

As an indirect measure of gastric emptying, the amount of peptone meal that had to be administered to the volunteers to continue the intragastric titration was quantified. The nasogastric tube was placed in a dependent area of the stomach in all the volunteers. There was no statistical difference $(P>0.05)$ in the amount of peptone meal that was added between the placebo and $\mathrm{M}-\mathrm{PGE}_{\text {, }}$ treated days, or between the different treatment groups.

No side-effects were observed except at the highest dose of $150 \mu \mathrm{g}$; at that dose, three out of five subjects experienced loose stools later on the same day. 
after 14 days of treatment. ${ }^{16}$ The present results suggest that still lower doses may promote healing and prevent relapses.

The anti-ulcer property of methyl analogues of $\mathrm{PGE}_{2}$ is likely to be due not only to inhibition of acid secretion but also to gastric cytoprotection produced by these agents. ${ }^{17}$ This dual mode of action should be particularly beneficial in the treatment of peptic ulcer.

We would like to thank Mark Paulson, RPh, for his help in preparation of the drug and peptone meal, Carl Metzler and Jennifer Harris for the statistical evaluation, and Mrs Margo Raifsnider for her secretarial help.

\section{References}

${ }^{1}$ Robert A, Nezamis JE, Phillips JP. Inhibition of gastric secretion by prostaglandins. Am J Dig Dis 1967; 12:1073-6.

${ }^{2}$ Robert A, Nezamis JE, Phillips JP. Effect of prostaglandin $\mathrm{E}_{1}$ on gastric secretion and ulcer formation in the rat. Gastroenterology 1968; 55:481-7.

${ }^{3}$ Nezamis JE, Robert A, Stowe DF. Inhibition by prostaglandin $E_{1}$ of gastric secretion in the dog. $J$ Physiol (Lond) 1971; 218:369-83.

${ }^{4}$ Wilson DE, Phillips C, Levine RA. Inhibition of gastric secretion in man by prostaglandin $\mathrm{A}_{1}$. Gastroenterology 1971; 61:201-6.

"Classen M, Koch H, Bickhardt J, Topf G, Demling L. The effect of prostaglandin $E_{1}$ on the pentagastrin-stimulated gastric secretion in man. Digestion $1971 ; 4: 333-44$.

"Horton EW, Main IHM, Thompson CJ, Wright PM. Effect of orally administered prostaglandin $E_{1}$ on gastric secretion and intestine motility in man. Gut 1968; 9:655-8.

'Karim SMM, Carter DC, Bhana D, Ganesan PA. Effect of orally administered prostaglandin $E_{2}$ and its 15-methyl analogues on gastric secretion. $\mathrm{Br}$ Med J 1963; 1:143-6.

-Robert A, Magerlein BJ. 15-methyl $\mathrm{PGE}_{2}$ and 16, 16-dimethyl $\mathrm{PGE}_{2}$ : potent inhibitors of gastric secretion. Adv Biosci 1973; 9:247-53.

'Robert A, Schultz JR, Nezamis JE, Lancaster C. Gastric antisecretory and antiulcer properties of $\mathrm{PGE}_{2}$ 15-methyl $\mathrm{PGE}_{2}$, and 16,16-dimethyl $\mathrm{PGE}_{2}$. Intravenous, oral and intrajejunal administration. Gastroenterology 1976; 70:359.

${ }^{10}$ Karim SMM, Carter DC, Bhana D, Ganesan PA. Effect of orally and intravenously administered prostaglandin $15(\mathrm{R})-15$ methyl $\mathrm{E}_{2}$ on gastric secretion in man. Adv Biosci 1963; 9:255-64.

${ }^{11}$ Peterson W, Feldman M, Taylor I, Brewer M. The effect of 15(R)-15-methyl prostaglandin $E_{2}$ on mealstimulated gastric acid secretion, serum gastrin, and pancreatic polypeptide in duodenal ulcer patients. Dig Dis Sci 1979; 24:381-4.

${ }^{12}$ Fordtran JS, Walsh JH. Gastric acid secretion rate and buffer content of the stomach after eating: results in normal subjects and in patients with duodenal ulcer. J Clin Invest 1963; 52:645-57.

${ }^{13}$ Gross RA, Isenberg JI, Hogan D, Samloff IM. Effect of fat on meal-stimulated duodenal acid load, duodenal pepsin load, and serum gastrin in duodenal ulcer and normal subjects. Gastroenterology 1978; 75:357--62.

${ }^{14}$ Fung WP, Karim SMM, Tye CY. Effect of 15(R)15-methyl prostaglandin $E_{2}$ methyl ester on healing of gastric ulcers. Controlled endoscopic study. Lancet 1974; 2:10-12.

1.:Rybicka J, Gibinski K. Methyl-prostaglandin $\mathrm{E}_{2}$ analogues for healing of gastroduodenal ulcers. Scand J Gastroenterol 1978; 13:155-9.

1; Vantrappen G, Popiela T, Tytgat DNJ, Lambert R, Robert A. A multicenter trial of 15(R)-15-methyl prostaglandin $\mathrm{E}_{2}$ in duodenal ulcer. Gastroenterology (In press).

${ }^{17}$ Robert A, Nezamis JE, Lancaster C, Hanchar AJ. Cytoprotection by prostaglandins in rats: prevention of gastric necrosis produced by alcohol, $\mathrm{HCl}, \mathrm{NaOH}$, hypertonic $\mathrm{NaCl}$, and thermal injury. Gastroenterology 1979; 77:433-43. 